\title{
sciendo
}

Transport and Telecommunication, 2021, volume 22, no. 2, 163-182

Transport and Telecommunication Institute, Lomonosova 1, Riga, LV-1019, Latvia DOI 10.2478/ttj-2021-0013

\section{INTELLIGENT TRAFFIC MANAGEMENT: A REVIEW OF CHALLENGES, SOLUTIONS, AND FUTURE PERSPECTIVES}

\author{
Roopa Ravish ${ }^{1}$, Shanta Ranga Swamy ${ }^{2}$ \\ ${ }^{I}$ Department of Computer Science and Engineering, PES University, \\ Bangalore, India \\ rooparavish@pes.edu \\ ${ }^{2}$ Department of Computer Science and Engineering, Rashtreeya Vidyalaya College of Engineering, \\ Bangalore, India \\ shantharangaswamy@rvce.edu.in
}

\begin{abstract}
Recent years have witnessed a colossal increase of vehicles on the roads; unfortunately, the infrastructure of roads and traffic systems has not kept pace with this growth, resulting in inefficient traffic management. Owing to this imbalance, traffic jams on roads, congestions, and pollution have shown a marked increase. The management of growing traffic is a major issue across the world. Intelligent Transportation Systems (ITS) have a great potential in offering solutions to such issues by using novel technologies. In this review, the ITS-based solutions for traffic management and control have been categorized as traffic data collection solutions, traffic management solutions, congestion avoidance solutions, and travel time prediction solutions. The solutions have been presented along with their underlying technologies, advantages, and drawbacks. First, important solutions for collecting traffic-related data and road conditions are discussed. Next, ITS solutions for the effective management of traffic are presented. Third, key strategies based on machine learning and computational intelligence for avoiding congestion are outlined. Fourth, important solutions for accurately predicting travel time are presented. Finally, avenues for future work in these areas are discussed.
\end{abstract}

Keywords: Congestion Management, Computational Intelligence, Intelligent Transport Systems, Intelligent Traffic Control, Traffic Data Collection, Traffic Management, Travel Time Prediction

\section{Introduction}

Congestion of traffic is a key problem faced in a majority of metro cities, especially in the developing world. Traffic congestion comprises of queues, reduced speeds, and increased travel durations, which fatigues commuters and results in stress, thereby bringing down productivity and creating intangible societal expenses (Emo et al., 2016). In addition, different factors, such as use of natural resources, surroundings, commuter safety, etc., are affected in either a direct or an indirect manner. Thus, congestion of traffic poses a challenge to every growing city. With the increasing congestion, the construction of new roads is seldom fruitful because of various circumstances. Contrarily, constructing new roads could often add to congestion by creating more demands for motor travel, thereby depleting the added capacity rapidly (Pfleiderer and Dieterich, 1995). This is getting increasingly evident as congestions with delays are being noticed in big cities. Thus, several mitigation measures are being implemented through the years.

The increasing challenges associated with traffic congestion attracted the attention of academicians, who have proposed numerous techniques for managing traffic and solving the congestion issue. Such solutions range from the latest data collecting equipment with wireless sensor network (WSN) protocols (Faye et al., 2012; Collotta et al., 2014) to route schemes (Chen et al., 2012; Bell et al., 2012) and traffic forecasting methods (Min and Wynter, 2011; Shen and Wynter, 2012). Several researchers were interested in the application of Intelligent Transportation Systems (ITS) to manage traffic management issues. Liang and Wakahara (2013) proposed city traffic prediction models using varied modeling methods, one based on the network traffic flow propagation, and the other based on the timevarying spare flow volume on the related road link. This paper investigates the technologies directed towards developing novel systems that address many of the traffic congestion problems. The findings of these researchers indicated that roads could be safer and greener with enhanced efficiency through the application of emerging ITS technologies (Sładkowski and Pamuła, 2016). However, several challenges are encountered during the implementation of ITS. 
Studies pointed out that effective control and management of traffic and accurate prediction of travel time are the two major challenges faced in the application of ITS. However, despite the emphasis on these challenges, only a few researchers have rendered solutions based on the functionality of ITS (Van Arem et al., 1997; Papageorgio et al., 2003; Barros et al., 2015; Chen and Chen, 2019). In addition, only few papers have compared the benefits and shortcomings of the suggested solutions (Chhatpar et al., 2018; De Souza et al., 2017; Avatefipour and Sadry, 2018). Therefore, in the current research paper, our objectives are as follows:

1) To present some important state-of-the-art ITS solutions for managing traffic congestion

2) To categorize ITS, based on their functionalities with working principles and underlying technologies

3) To provide insights on the drawbacks and benefits of the current ITS proposals and help stakeholders to select the technology for adoption

4) To provide future directions

Having conducted an in-depth survey of previous empirical studies in this area, the outcomes of this study contributes to the current knowledge of traffic management by providing a novel perspective on its functional constructs. This research also contributes to the existing literature by rendering critical insights into the pros and cons of the existing systems, thereby aiding decision makers in the selection of technologies for their cities.

The rest of the paper is organized as follows: the first section deals with the process of this review, the next section deals with effective traffic control and management by using ITS, and the subsequent subsections deal with traffic data collection, congestion management, congestion avoidance, and accurate prediction of travel time. Finally, the conclusions and directions for future work are discussed.

\section{Review Process}

A detailed classification and analysis of literature was considered as a part of the current research. The following methodology was adopted:

1) The database was updated by selecting the latest literature. The collected literature was reviewed until June 2019.

2) Both hard copies in reputed local libraries and soft copies from the Internet were accessed for the literature review.

3) Popular search engines, such as www.google.com, www.altavista.com, etc., were employed to gather the subject-related literature from a multitude of sources. Although it has been attempted to include as many relevant works as possible, this list is by no means either complete or exhaustive.

4) The classification scheme was developed by looking at the nature of the studies. Later, the studies were examined to detect commonalities, content, advantages, and disadvantages.

5) Finally, the studies were examined with a view to suggest future avenues for research.

\section{Effective Traffic Control and Management using ITS}

ITS attempts to blend network-related data, such as vehicular cloud computing (Shojafar et al., 2016), WSN (Cordeschi et al., 2015), and other approaches, in a seamless manner for managing traffic effectively. The traffic congestion handling solution by ITS can be functionally categorized as traffic data collection, traffic management, congestion avoidance, and travel time prediction (Figure 1). The subsequent subsections provide the review of studies that examined the techniques used for delivering these functions.

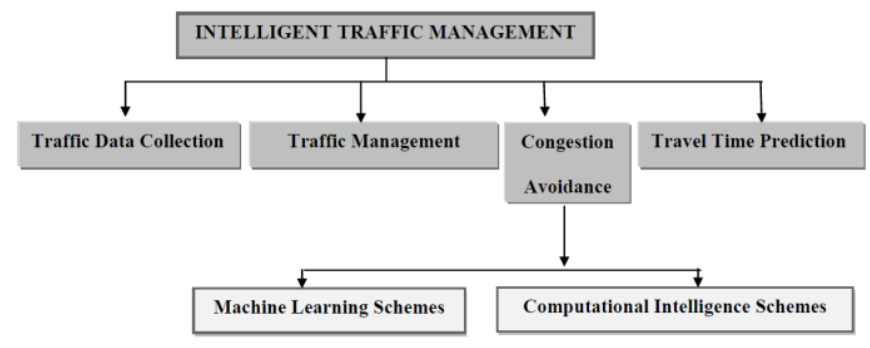

Figure 1. Functional categories for congestion management solutions by using ITS 


\subsection{Traffic Data with Travel Time Constraints}

Collection of traffic data is one of the primary and important functions in managing the traffic as all other traffic management procedures rely on the accurate prediction of traffic. Several researchers proposed numerous methods to collect the data related to traffic and road conditions. One of the common methods used for the collection of data is the use of sensors fixed at a specific location. Sen et al. (2009) developed a data collection system by placing a microphone on the roadside to record the sounds of vehicular honks for estimating the congestion level. However, error in the accuracy of sensing congestion during multiple and simultaneous vehicular honking restricted this technique. Na et al. (2015) modified the technology by using a module comprising of 37 microphones. Despite the fair outcomes in bad weathers and poor light, its high cost and limitations in determining congestion accuracy during high vehicular movement limited its use. The development of machine learning and artificial intelligence changed the design of sensors and Fan et al. (2018) developed a sensor for collecting the data to detect vehicular congestion by using machine-learning technology. These sensors were placed at various toll collection centers. The findings revealed better results when compared to other sensors. However, higher costs limited its application.

Adaptive architecture framework was another technology proposed by Khan (2017) to gather traffic data. This technology focused on detecting bus traffic. The author stated that the selection of private or public mode of transportation depends upon one's lifestyle and it is the responsibility of ITS to balance both. However, the use of private vehicles has a direct impact on congestion. If potential public transport issues are solved, then a perfect balance could be achieved to build software, such as Global Positioning System (GPS), Connected Vehicle (CV), Sensor-based, and Internet of Vehicles (IoV). Increase in the usage of smart devices and vast improvements in wireless technology have facilitated the application of GPS-based wireless techniques and the usage of positional coordinates for collecting vehicle-related data.

Haferkamp et al. (2017) proposed a vehicular data collection technique using wireless networks. Received Signal Strength Indicator (RSSI) was used to detect vehicles and classify vehicle types. RSSI performed well with high detection accuracy. However, the antenna-related expenses restricted its application to a certain extent. Bernas (2018) updated the wireless network-based vehicle detection systems by using more transmitters and receivers to gain more data with higher accuracy. Despite its good performance, the application of this system was restricted due to high expenses. Still, these wireless-based data collection and vehicle detection systems are largely considered as optimal to control traffic congestion. In addition to these techniques, Ghosh et al. (2015) proposed seismometer-based and geophone-based technology to detect vehicles. However, the fall of detection window prior to the event completion was considered as its prime drawback, which in turn restricted its application. Furthermore, Rivas et al. (2017) proposed a piezoelectric technologies-based technique that had drawbacks, such as high susceptibility to weather conditions and low efficiency.

In brief, it can be pointed out that despite the utilization of numerous techniques to collect data and detect vehicles, the application of such techniques relied on the specific nature of the location where the traffic has to be managed. Hence, the design of the data collection module largely depends on the requirement of the specific locations. Table 1 summarizes the technologies used in collecting trafficrelated data.

Table 1. Summary of technologies adopted for gathering traffic data

\begin{tabular}{|l|l|l|l|l|}
\hline Reference & Technology & Principles & Advantages & Disadvantages \\
\hline Khan (2017) & $\begin{array}{l}\text { Adaptive architecture } \\
\text { framework }\end{array}$ & $\begin{array}{l}\text { Use of Data Mining } \\
\text { techniques and } \\
\text { Machine Learning } \\
\text { agorithms for traffic } \\
\text { monitoring }\end{array}$ & $\begin{array}{l}\text { No changes in the } \\
\text { existing system needed. } \\
\text { Real-time monitoring } \\
\text { of buses and routes }\end{array}$ & $\begin{array}{l}\text { Influx of new data sources } \\
\text { will impact whole life cycle } \\
\text { of data and performance of } \\
\text { data acquisition }\end{array}$ \\
\hline $\begin{array}{l}\text { Fan } \text { et al. } \\
(2018)\end{array}$ & $\begin{array}{l}\text { Machine learning and } \\
\text { big data }\end{array}$ & $\begin{array}{l}\text { Vehicles are equipped } \\
\text { with sensors which } \\
\text { provide real-time data }\end{array}$ & Simple and economical & $\begin{array}{l}\text { Accuracy and reliability } \\
\text { issues when traffic volumes } \\
\text { and density fluctuate }\end{array}$ \\
\hline $\begin{array}{l}\text { Sen } \text { et al. } \\
(2009)\end{array}$ & $\begin{array}{l}\text { Sound recording } \\
\text { (microphones) }\end{array}$ & $\begin{array}{l}\text { Assessment of Doppler } \\
\text { shift of vehicular honks }\end{array}$ & $\begin{array}{l}\text { Economical, can be } \\
\text { used where traffic is } \\
\text { unorganized }\end{array}$ & $\begin{array}{l}\text { Error in results as vehicle } \\
\text { speeds increase, overlapping } \\
\text { honks will affect results }\end{array}$ \\
\hline $\begin{array}{l}\text { Mohan } \text { et al. } \\
(2008)\end{array}$ & $\begin{array}{l}\text { GPS, accelerometer, } \\
\text { and microphone }\end{array}$ & $\begin{array}{l}\text { The developed Nericell } \\
\text { virtually reorients the } \\
\text { accelerometer on a } \\
\text { smartphone, and } \\
\text { detects honks and does } \\
\text { localization. }\end{array}$ & $\begin{array}{l}\text { Energy efficient, } \\
\text { suitable for bad roads, } \\
\text { chaotic traffic }\end{array}$ & $\begin{array}{l}\text { Privacy concerns of } \\
\text { smartphone users, getting } \\
\text { users to participate in the } \\
\text { shared system }\end{array}$ \\
\hline
\end{tabular}




\begin{tabular}{|l|l|l|l|l|}
\hline Reference & Technology & Principles & Advantages & Disadvantages \\
\hline $\begin{array}{l}\text { Haferkamp } \\
\text { et al. }(2017)\end{array}$ & $\begin{array}{l}\text { Wireless network with } \\
\text { three transmitters and } \\
\text { receivers }\end{array}$ & $\begin{array}{l}\text { RSSI information is } \\
\text { used for detecting } \\
\text { vehicles and classifying } \\
\text { vehicle type. }\end{array}$ & $\begin{array}{l}\text { High classifying } \\
\text { accuracy }\end{array}$ & $\begin{array}{l}\text { The directional antennae } \\
\text { utilized makes it expensive. }\end{array}$ \\
\hline $\begin{array}{l}\text { Bernas } \text { et al. } \\
(2018)\end{array}$ & $\begin{array}{l}\text { Wireless network using } \\
\text { four transmitters and } \\
\text { receivers }\end{array}$ & $\begin{array}{l}\text { RSSI information is } \\
\text { used for detecting } \\
\text { vehicles and classifying } \\
\text { vehicle type. }\end{array}$ & $\begin{array}{l}\text { High classifying } \\
\text { accuracy, low energy } \\
\text { consumption, easy } \\
\text { installation }\end{array}$ & $\begin{array}{l}\text { The utilized directional } \\
\text { antennae makes it } \\
\text { expensive. }\end{array}$ \\
\hline $\begin{array}{l}\text { Rivas } \text { et al. } \\
(2017)\end{array}$ & $\begin{array}{l}\text { Piezoelectric } \\
\text { acceleration sensors }\end{array}$ & $\begin{array}{l}\text { Algorithms analyze the } \\
\text { amplitudes and } \\
\text { frequency range of } \\
\text { vibrations }\end{array}$ & $\begin{array}{l}\text { Economical, high } \\
\text { accuracy }\end{array}$ & $\begin{array}{l}\text { Weather conditions could } \\
\text { affect efficiency }\end{array}$ \\
\hline $\begin{array}{l}\text { Ghosh } \text { et al. } \\
(2015)\end{array}$ & $\begin{array}{l}\text { Seismometer and } \\
\text { geophone }\end{array}$ & $\begin{array}{l}\text { Pseudo-Wigner-Ville } \\
\text { Rényi entropy method } \\
\text { with an enhanced } \\
\text { CFAR detector for } \\
\text { seismic waves }\end{array}$ & $\begin{array}{l}\text { Minimal false alarms, } \\
\text { good detection }\end{array}$ & $\begin{array}{l}\text { CFAR threshold increases } \\
\text { as CPA is approached, } \\
\text { causing fall of detection } \\
\text { window prior to event } \\
\text { completion }\end{array}$ \\
\hline $\begin{array}{l}\text { Na } \text { et al. } \\
(2015)\end{array}$ & $\begin{array}{l}\text { Thirty seven- } \\
\text { microphone } \\
\text { arrangement }\end{array}$ & $\begin{array}{l}\text { Can function even in } \\
\text { poor light and adverse } \\
\text { weather }\end{array}$ & $\begin{array}{l}\text { High costs of equipment, } \\
\text { accuracy limitations }\end{array}$ \\
\hline
\end{tabular}

\subsection{Traffic Management Systems}

Traffic Management System (TMS) is concerned with the organizing, arranging, guiding, and controlling of traffic, both moving and stationary, along with other vehicles, cyclists, and pedestrians. TMS aims to ensure safety, orderliness, and efficiency during the movement of people and goods, and enhance the quality of environment around traffic locations (Underwood, 1990). The present section deals with ITS solutions for effectively managing traffic and the drawbacks associated with their functioning.

WSNs are being increasingly used for detecting traffic and avoiding congestion. WSNs are effective because of their fast data transfer, simple installation, minimal maintenance, small size, and cost-effectiveness, when compared with other network choices. Considerable research has been conducted on TMS by using WSNs for avoiding congestion, enabling priority for emergency vans, and reducing waiting time of vehicles at signals.

Friesen et al. (2004) proposed a comprehensive data collection mechanism. This system uses different WSN devices and technologies for gathering information at the main traffic signals in urban areas. Vehicular count and trajectory data are gathered by using a Bluetooth mechanism, and this data is forwarded to a master node that handles all received data through an IEEE 802.15.4 protocol. The realtime data is sent by the node to a server at a five-minute interval through a cellular phone having GSM. This data is saved in the database and retrieved by users to obtain the required real-time data. It is evidenced that Bluetooth tracking is a reliable way of monitoring traffic and vehicles in real time. However, this method suffered low data rate and short-range problems along with severe security issues.

Saqib and Lee (2010) proposed an application, which estimated the vehicular location and speed by employing WSNs. Anchor sensing nodes were employed as pavement readers. As soon as a moving vehicle came within the operational range of the nodes, the positional signal was transmitted by using a symmetrical two-sided range algorithm. The speed of the vehicles is estimated by measuring the locations at varied intervals. This suggested model was found to be more economical than other models for detecting the location and speed of vehicles. However, increased error rate during higher traffic flow restricted its usage.

A user-dependent traffic data-gathering strategy relying on WSNs was suggested by Zhou et al. (2013) in a study for achieving a compromise between the sensor power consumed and the delay in delivering data by employing every routing feature for decision-making. However, security issues and low data rate were its major drawbacks, which limited its scope.

Ahmad et al. (2013) suggested a traffic management technique by using a channel switching approach for reducing communication expenses and power consumption. Simulation for this suggested model was conducted by using OPNET. It was seen that that the model could be feasibly implemented at traffic signals. However, the proposed solution failed due to the interference of vehicle-to-vehicle channels.

Bruno and Nurchis (2013) developed two useful data gathering algorithms: Probabilistic Data Collection (PDC) for vehicle multimedia SNs and GREEDY. The researchers simulated this algorithm by using VANET MobiSim and NS-2 simulator. The output indicated that the GREEDY algorithm could 
cover more uniformly while consuming reduced network bandwidth. However, these techniques failed to consider cooperative storage among vehicles and image replications. This in turn could significantly affect the accuracy of data collection and hence this proposal was not much appreciated.

Another technology used in managing the traffic is RFID-based intelligent system. Chao and Chen (2014) presented a RFID-based intelligent TMS for determining traffic movement. The proposed intelligent traffic light control system (ITLCS) uses an RFID system, which complies with the IEEE 802.11p protocol for detecting the number of vehicles and finding the time spent by vehicles on main roads and on side roads, passing through the intersection throughout the period of a green light. They used Zig Bee modules to send real time data like weather conditions and the vehicle registration information to the regional control center. The proposed system could perform remote transmission and reduce traffic accidents. However, despite a fair attempt, the scope of using Zig Bee for data transfer was restricted because Zig Bee always displayed a very low data transfer rate that could hamper accuracy.

Another technique named as optimal VSN routing strategy was proposed by Choi et al. (2015) in an attempt to design a traffic management system. The researchers studied the factors that influence the delay performance in VSNs. They formulated the packet routing problem as a Markov Decision Process (MDP) and developed an Optimal VSN Data Forwarding (OVDF) algorithm. They conducted simulations on a GloMoSim simulator. They compared the performance of OVDF with the Vehicle Assisted Data Delivery (VADD) algorithm and Trajectory Based Data (TBD) forwarding scheme. The simulation results demonstrated that the OVDF gave the best sensing coverage and a higher packet delivery ratio, and reduced the delay about $25 \%$ and $20 \%$ when compared to VADD and TBD, respectively. Despite such high performances, increased error during higher traffic casted some shadow on its applicability.

In a recent study, Barthélemy et al. (2019) utilized edge-computing technologies. The study yielded satisfactory results in managing the traffic with advantages, such as multi-modal detection, privacy compliance, scalability, and interoperability. However, certain operational issues in bad weather and low light constituted its drawbacks. The strategies used for traffic management are summarized in Table 2.

Table 2. Summary of technologies used for managing traffic

\begin{tabular}{|c|c|c|c|c|}
\hline Authors & Technology & Principle & Advantages & Disadvantages \\
\hline $\begin{array}{l}\text { Bruno and } \\
\text { Nurchis (2013) }\end{array}$ & $\begin{array}{l}\text { Multiple mobile } \\
\text { cameras }\end{array}$ & $\begin{array}{l}\text { Use of Probabilistic Data } \\
\text { Collection and GREEDY } \\
\text { algorithm for collecting } \\
\text { data, and analysis of } \\
\text { collected images }\end{array}$ & $\begin{array}{l}\text { Coverage more uniform, } \\
\text { consumes less network } \\
\text { bandwidth }\end{array}$ & $\begin{array}{l}\text { Does not consider } \\
\text { cooperative storage } \\
\text { among vehicles and image } \\
\text { replications }\end{array}$ \\
\hline $\begin{array}{l}\text { Chao and Chen } \\
(2014)\end{array}$ & $\begin{array}{l}\text { IRFID system, } \\
\text { ZigBee wireless } \\
\text { network } \\
\text { communication }\end{array}$ & $\begin{array}{l}\text { RFID detects traffic flow, } \\
\text { and a sensor analyzes data } \\
\text { for traffic control using an } \\
\text { extension algorithm }\end{array}$ & $\begin{array}{l}\text { Performs remote } \\
\text { transmission and reduces } \\
\text { traffic accidents, power } \\
\text { savings, and scalable. }\end{array}$ & $\begin{array}{l}\text { Zigbee systems have low } \\
\text { data transfer rates that } \\
\text { could hamper accuracy }\end{array}$ \\
\hline $\begin{array}{l}\text { Saqib and Lee } \\
(2010)\end{array}$ & WSN & $\begin{array}{l}\text { Two anchor nodes placed } \\
\text { at fixed distance. A } \\
\text { symmetric double-sided } \\
\text { two-way ranging } \\
\text { algorithm gives location } \\
\text { of vehicle }\end{array}$ & $\begin{array}{l}\text { Economical, robust, and } \\
\text { requires lesser } \\
\text { computation }\end{array}$ & $\begin{array}{l}\text { Errors when traffic is } \\
\text { heavy }\end{array}$ \\
\hline Choi et al. (2015) & $\begin{array}{l}\text { Markov Decision } \\
\text { Process and } \\
\text { Optimal VSN } \\
\text { Data Forwarding }\end{array}$ & $\begin{array}{l}\text { A road network graph } \\
\text { model captures the vehicle } \\
\text { effects having } \\
\text { predetermined trajectories } \\
\text { and creates an easy } \\
\text { routing problem } \\
\text { formulation }\end{array}$ & $\begin{array}{l}\text { Highr packet delivery } \\
\text { ratio, reduced delay }\end{array}$ & $\begin{array}{l}\text { Errors when traffic is } \\
\text { heavy }\end{array}$ \\
\hline $\begin{array}{l}\text { Friesen et al. } \\
(2004)\end{array}$ & WSN & $\begin{array}{l}\text { Slave probes transmit } \\
\text { traffic data to a master } \\
\text { node using XBee } \\
\text { communication, and is } \\
\text { forwarded to a central } \\
\text { server by a GSM network }\end{array}$ & $\begin{array}{l}\text { Monitoring traffic in real } \\
\text { time using Bluetooth }\end{array}$ & $\begin{array}{l}\text { Low data rate, short range, } \\
\text { security issues }\end{array}$ \\
\hline $\begin{array}{l}\text { Zhou et al. } \\
\text { (2013) }\end{array}$ & WSN & $\begin{array}{l}\text { Three sensor nodes collect } \\
\text { and deliver data. A user- } \\
\text { driven data-centric } \\
\text { strategy for routing } \\
\text { considers multi-routing } \\
\text { data for taking decisions } \\
\text { for meeting various user } \\
\text { needs }\end{array}$ & $\begin{array}{l}\text { Balances sensor power } \\
\text { consumed and data delay } \\
\text { duration }\end{array}$ & $\begin{array}{l}\text { Low data rate, short range, } \\
\text { security issues }\end{array}$ \\
\hline
\end{tabular}




\begin{tabular}{|c|c|c|c|c|}
\hline Authors & Technology & Principle & Advantages & Disadvantages \\
\hline $\begin{array}{l}\text { Ahmad et al. } \\
(2013)\end{array}$ & WSN & $\begin{array}{l}\text { Nodes are located in } \\
\text { vehicles which interact } \\
\text { with road side receivers } \\
\text { that transmit the data to } \\
\text { coordinating modules. A } \\
\text { robust channel switching } \\
\text { method minimizes the } \\
\text { energy consumed, } \\
\text { response duration, and } \\
\text { connecting delays }\end{array}$ & $\begin{array}{l}\text { Reduces communication } \\
\text { expenses and power } \\
\text { consumed }\end{array}$ & $\begin{array}{l}\text { Prone to intra-channel } \\
\text { interference, security } \\
\text { issues }\end{array}$ \\
\hline $\begin{array}{l}\text { Barthélemy et al. } \\
\text { (2019) }\end{array}$ & $\begin{array}{l}\text { Edge } \\
\text { computation }\end{array}$ & $\begin{array}{l}\text { An edge-computing } \\
\text { equipment uses deep } \\
\text { neural networks and } \\
\text { computer vision for } \\
\text { tracking traffic in real- } \\
\text { time. The interoperable } \\
\text { Agnosticity framework } \\
\text { gathers, stores, and } \\
\text { manages data from } \\
\text { different sensors }\end{array}$ & $\begin{array}{l}\text { Multi-modal detection, } \\
\text { privacy compliance, } \\
\text { scalable, and interoperable }\end{array}$ & $\begin{array}{l}\text { Operational issues in low } \\
\text { light and bad weather }\end{array}$ \\
\hline Won et al. (2019) & Wi-Fi & $\begin{array}{l}\text { Two WiFi transceivers } \\
\text { capture data. A } \\
\text { convolutional neural } \\
\text { network and principal } \\
\text { component analysis based } \\
\text { algorithm captures the } \\
\text { vehicles in the data }\end{array}$ & $\begin{array}{l}\text { Reduced energy } \\
\text { consumption, minimal } \\
\text { connectivity delay and } \\
\text { reduced interference from } \\
\text { nearby intersections }\end{array}$ & $\begin{array}{l}\text { Not suitable where traffic } \\
\text { is heavy }\end{array}$ \\
\hline
\end{tabular}

\subsection{Congestion Avoidance Schemes}

Traffic congestion occurs when road usage increases. Many strategies and methods, which are based on machine learning and computational intelligence, have been suggested to prevent congestion. The key studies are presented here.

\section{Managing Vehicular Networks with Machine learning}

Often, effective rerouting strategies are necessary when traffic networks are congested. This section describes some key approaches proposed in the literature, which use machine-learning approaches.

Araújo et al. (2014) proposed a cooperative vehicular traffic congestion identification and minimization scheme for reducing traffic congestion. The study employed vehicle-to-vehicle communication and the data was gathered from all vehicles and processed by fuzzy logic. The paths of vehicles were modified after the probability of congestion was identified, resulting in the minimization of congestion. However, the major drawback was that the technique failed to detect accidents, which can be a prime cause for congestion.

Meneguette et al. (2015) proposed an urban congestion identifying technique for reducing traffic jams by using vehicle-to-vehicle communication along with Artificial Neural Networks (ANN). The algorithm detected and classified the levels of congestion on the streets. The ANN processed the velocity and flow density as inputs and returned the congestion level as output, which was transmitted to all vehicles. However, the technique lacked accuracy during high traffic and did not detect accidents.

De Souza et al. (2015) proposed the application of cooperative rerouting algorithm that runs on KNearest Neighbor for preventing congestion and improving traffic by using vehicle-to-infrastructure communication. The algorithm detected congestion, classified the traffic, and suggested an alternate route. However, the technique displayed poor traffic balance, which in turn restricted its scope.

De Souza et al. (2016) proposed an algorithm for avoiding congestion by using a traffic classifying method with rerouting called CHIMERA. It used vehicle-to-infrastructure communication, along with the probabilistic K-Shortest Path method and worked out other routes for users. Although the technique reduced the average trip time, stop time, and distance, its scope was hindered by poor traffic balance.

Ma et al. (2017) proposed the Convolution Neural Networking (CNN) algorithm to identify congestion and manage traffic. Despite a satisfactory performance in large networks with high accuracy, the application of CNN was restricted due to the lag in training time, which caused delay in detection of congestion.

As a means to overcome the drawbacks of CNN in detecting the congestion, Chung and Sohn (2018) proposed deep CNN model. The model used supervised learning (deep convolution neural network) for counting the number of vehicles on a strip of road, based on video imagery. The method 
collectively counted the vehicles in a human-like manner. The findings revealed that the proposed deep CNN provided congestion reports with fair accuracy and smaller time lag. However, deep CNN could not distinguish between moving vehicles and stationary vehicles.

Perez-Murueta et al. (2019) proposed the application of another deep learning technique for detecting traffic congestion. The authors proposed deep learning and k-shortest path algorithm to detect traffic congestion. However, the findings revealed that the proposed technique could not scale the intensity of traffic.

Table 3. Summary of machine learning approaches to mitigate congestion

\begin{tabular}{|c|c|c|c|c|}
\hline Reference & Algorithm & Principle & Advantages & Disadvantages \\
\hline $\begin{array}{l}\text { Chowdhury } \\
\text { et al. (2018) }\end{array}$ & PROPHET & $\begin{array}{l}\text { Data from node of adjacent road is subjected } \\
\text { to Time Series analysis, where node } \\
\text { information contains the traffic density of all } \\
\text { incoming lanes of an intersection (node). } \\
\text { Prediction done by using PROPHET } \\
\text { algorithm }\end{array}$ & $\begin{array}{l}\text { Accurate results, } \\
\text { easy installation }\end{array}$ & $\begin{array}{l}\text { Heavy traffic and } \\
\text { bad weather could } \\
\text { affect results. } \\
\text { Sensors are } \\
\text { expensive }\end{array}$ \\
\hline $\begin{array}{l}\text { Araújo et al. } \\
(2014)\end{array}$ & Fuzzy logic & $\begin{array}{l}\text { For effective identification of traffic } \\
\text { congestion, an algorithm CARTIM is used } \\
\text { that uses a fuzzy logic-based system. The } \\
\text { method effectively employs the collaborative } \\
\text { communicating channel, avoiding } \\
\text { overloading }\end{array}$ & $\begin{array}{l}\text { Effective } \\
\text { congestion } \\
\text { identification and } \\
\text { minimization }\end{array}$ & $\begin{array}{l}\text { No accident } \\
\text { detection, limited } \\
\text { awareness of traffic } \\
\text { conditions }\end{array}$ \\
\hline $\begin{array}{l}\text { Meneguette } \\
\text { et al. }(2014)\end{array}$ & $\begin{array}{l}\text { Artificial } \\
\text { Neural } \\
\text { Networks } \\
\text { (ANN) }\end{array}$ & $\begin{array}{l}\text { The solution intelligent protocol of } \\
\text { congestion detection (INCIDENT) uses } \\
\text { ANN for (i) identifying the various levels of } \\
\text { congestion; (ii) categorizing these congestion } \\
\text { levels, and (iii) proposing new paths for } \\
\text { avoiding congestion }\end{array}$ & & $\begin{array}{l}\text { No accident } \\
\text { detection, not very } \\
\text { effective for heavy } \\
\text { traffic }\end{array}$ \\
\hline $\begin{array}{l}\text { De Souza et al. } \\
(2016)\end{array}$ & $\begin{array}{l}\text { k-Nearest } \\
\text { Neighbour } \\
(\mathrm{KNN})\end{array}$ & $\begin{array}{l}\text { Authors proposed the congestion avoidance } \\
\text { through a traffic classification mechanism } \\
\text { and a re-routing algorithm (CHIMERA). The } \\
\text { k-NN algorithm used by CHIMERA utilizes } \\
\text { the density of vehicles and average road } \\
\text { speed as inputs, and detects congestions }\end{array}$ & $\begin{array}{l}\text { Reduces average } \\
\text { trip time, stop } \\
\text { time, and distance }\end{array}$ & $\begin{array}{l}\text { Traffic balance is } \\
\text { poor }\end{array}$ \\
\hline $\begin{array}{l}\text { De Souza et al. } \\
(2015)\end{array}$ & $\mathrm{KNN}$ & $\begin{array}{l}\text { Same as above, except that a cooperative } \\
\text { algorithm suggests an alternative path }\end{array}$ & $\begin{array}{l}\text { Reduces average } \\
\text { trip time, stop } \\
\text { time, and distance, } \\
\text { better traffic } \\
\text { balance. }\end{array}$ & $\begin{array}{l}\text { Scalability issues, } \\
\text { sensitive to noisy } \\
\text { data }\end{array}$ \\
\hline $\begin{array}{l}\text { Ma et al. } \\
(2017)\end{array}$ & $\mathrm{CNN}$ & $\begin{array}{l}\text { Spatio-temporal vehicular dynamics are } \\
\text { transformed to imagery detailing the } \\
\text { time/space relations of flowing traffic by } 2-\mathrm{D} \\
\text { time-space matrices. CNN extracts abstract } \\
\text { traffic characteristics and predicts traffic } \\
\text { speed in the network }\end{array}$ & $\begin{array}{l}\text { Works well in } \\
\text { large scale } \\
\text { networks, good } \\
\text { accuracy }\end{array}$ & $\begin{array}{l}\text { Training time is } \\
\text { more }\end{array}$ \\
\hline Hong (2011) & Support Vector & $\begin{array}{l}\text { Model integrates the seasonal support vector } \\
\text { regression model and chaotic simulated } \\
\text { annealing algorithm for predicting traffic } \\
\text { flow }\end{array}$ & Accurate forecasts & $\begin{array}{l}\text { Long response time, } \\
\text { considerable } \\
\text { computer memory } \\
\text { consumed on } \\
\text { training }\end{array}$ \\
\hline $\begin{array}{l}\text { Ke et al. } \\
(2017)\end{array}$ & $\begin{array}{l}\text { Connected } \\
\text { graphs, and k- } \\
\text { means } \\
\text { clustering }\end{array}$ & $\begin{array}{l}\text { Parameters for traffic flow, e.g. speed, } \\
\text { volume, with density are collected from } \\
\text { UAV videos. The model detects the traffic } \\
\text { flow directions and evaluates stream } \\
\text { parameters separately. The model employs } \\
\text { KLT tracker, connected graphs, and k-means } \\
\text { clustering }\end{array}$ & $\begin{array}{l}\text { Accurate traffic } \\
\text { speed and vehicle } \\
\text { count }\end{array}$ & $\begin{array}{l}\text { Not effective in } \\
\text { heavy traffic and } \\
\text { curved roads }\end{array}$ \\
\hline $\begin{array}{l}\text { Raj et al. } \\
(2016)\end{array}$ & $\mathrm{KNN}, \mathrm{ANN}$ & $\begin{array}{l}\text { Traffic density is estimated using positional } \\
\text { sensors that can measure parameters like } \\
\text { volume and mean speed time. The model } \\
\text { uses KNN and ANN for estimating and } \\
\text { predicting purposes }\end{array}$ & $\begin{array}{l}\text { Lesser mean } \\
\text { absolute } \\
\text { percentage errors } \\
\text { (MAPEs) }\end{array}$ & $\begin{array}{l}\text { Scalability issues, } \\
\text { sensitive to noisy } \\
\text { data }\end{array}$ \\
\hline $\begin{array}{l}\text { Chung and } \\
\text { Sohn (2018) }\end{array}$ & Deep CNN & $\begin{array}{l}\text { The model uses a supervised learning (deep } \\
\text { convolutional neural network) for counting } \\
\text { the number of vehicles on a strip of road } \\
\text { based on video imagery. The method } \\
\text { collectively counts the vehicles in a human- } \\
\text { like manner }\end{array}$ & Acccurate & $\begin{array}{l}\text { Cannot distinguish } \\
\text { between moving } \\
\text { and stopped } \\
\text { vehicles }\end{array}$ \\
\hline
\end{tabular}




\begin{tabular}{|c|c|c|c|c|}
\hline Reference & Algorithm & Principle & Advantages & Disadvantages \\
\hline $\begin{array}{l}\text { Zhang et al. } \\
\text { (2017) }\end{array}$ & FCN & $\begin{array}{l}\text { The fully convolutional networks (FCN) } \\
\text { method used on webcam images estimates } \\
\text { vehicle count and density using a framework } \\
\text { for residual learning for performing end-to- } \\
\text { end density forecasting, permitting random } \\
\text { image resolution, while adapting to varying } \\
\text { vehicle perspectives and scales }\end{array}$ & $\begin{array}{l}\text { Significant } \\
\text { reduction of } \\
\text { MAPEs compared } \\
\text { to other methods }\end{array}$ & Lacks robustness \\
\hline $\begin{array}{l}\text { Zonoozi et al. } \\
(2018)\end{array}$ & $\begin{array}{l}\text { Periodic- } \\
\text { Convolutional } \\
\text { Recurrent } \\
\text { Network (P- } \\
\text { CRN) }\end{array}$ & $\begin{array}{l}\text { The model uses P-CRN to forecast traffic } \\
\text { density. P-CRN integrates with CRN to } \\
\text { capture temporal and spatial correlations } \\
\text { precisely, it performs learning and } \\
\text { incorporating of clear periodic } \\
\text { representations and optimization can be done } \\
\text { using multi-stage ahead forecasting }\end{array}$ & Good accuracy & $\begin{array}{l}\text { Not effective in } \\
\text { poor light } \\
\text { conditions }\end{array}$ \\
\hline $\begin{array}{l}\text { Perez-Murueta } \\
\text { et al. (2019) }\end{array}$ & $\begin{array}{l}\text { Deep learning, } \\
\text { k Shortest Path } \\
\text { algorithm }\end{array}$ & $\begin{array}{l}\text { The vehicle redirection model for avoiding } \\
\text { congestion employs deep learning to forecast } \\
\text { the state of the traffic network, and this data } \\
\text { identifies the areas, which could be } \\
\text { congested. Vehicles that are going to cross } \\
\text { these areas are redirected through alternate } \\
\text { routes created by entropy-balanced k } \\
\text { Shortest Path algorithm. The model uses data } \\
\text { collected in real time by a group of probe } \\
\text { cars for identifying non-recurring } \\
\text { congestions }\end{array}$ & $\begin{array}{l}\text { Inexpensive, easy } \\
\text { to implement }\end{array}$ & Not scalable \\
\hline
\end{tabular}

\section{Managing Networks with Computational Intelligence}

Of late, Computational Intelligence (CI), which is a computational technique and algorithm derived from nature, has been employed for managing traffic and reducing congestion. Among such traffic management approaches, ant, bee, and genetic algorithms are widely used for Vehicle Traffic Routing (VTR). The following subsections provide the review of the studies, which used any of these algorithms to detect and manage traffic congestion.

\section{Ant algorithms}

Cong et al. (2013) proposed ant colony routing, a forecast-based method, which utilized colored ants with stench pheromone for routing vehicles and reducing congestion. The stench pheromone is used for distributing vehicles using street maps. The findings revealed effective detection of vehicles on the streets. However, difficulties in theoretical analysis restricted the application of ant colony routing.

Jabbarpour et al. (2014) proposed the ant-guided congestion prevention algorithm that segments maps and mean travelling speed forecasts to minimize congestion by arriving at the minimally congested nearest paths. On simulation, the algorithm surpassed current methods in speed and mean travel duration, and managed non-repeating congestion better. However, the variation in probability distribution with respect to different iterations limited the detection accuracy.

Wang et al. (2015) proposed the multi-metric ant colony optimization algorithm, an ant colony VTR system, which utilizes the least distance and time, optimal road situation, or the combined sequence, suited to users' preferences (pheromones), to consider real-time data for the VTR process. The algorithm uses the TOPSIS algorithm to select the optimal route. The findings revealed that the proposed algorithm achieved suitable routes as per the varied requirements in an easy and rapid manner.

Bee

Bee algorithms are derived from the foraging nature of bees. Artificial bees (ABs) collectively find solutions to intricate optimization issues in bee algorithms. Like ants, two directions, i.e., forward and reverse, are assigned to nectar-seeking ABs. Forward implies that ABs are positioned in the origin and search their environment individually by creating many partial solutions. Reverse implies that ABs return to their origins from their destinations and decide as a group.

Teodorović and DellOrco (2008) proposed a bee algorithm for solving the ride-matching issue, and thus, the road congestion issue. Ride-matching assists commuters in sharing a vehicle during their travel to destinations, and thus minimizes the number of vehicles. Consequently, money is saved and stress and travel duration is reduced. However, slow convergence for local minima restricted the scope of the bee algorithm.

Wedde and Senge (2007) proposed the distributed and self-organized Bee Jam algorithm for VTR. This algorithm is a multi-bee VTR system created for reducing vehicular travel duration by avoiding 
congestions. It gathers the latest and real-time traffic data by employing vehicle-to-infrastructure communications. The findings revealed that Bee Jam algorithm succeeded in reducing travel time to a great extent. However, the random initialization nature affects accuracy in the detection of vehicles.

\section{Genetic Algorithms}

Genetic algorithms are based on populations that provide possible solutions as chromosomes. All chromosomes comprise of a group of items that provide a group of solutions for optimizing variables. The evaluation of the suitability of every solution is carried out by an objective function. The three essential operations of genetic algorithms are selecting, crossing over, and mutating.

Wen et al. (2011) developed a multi-objective VTR system that employed distance, cost, and time as the objectives for locating routes and named it as the distance-Pareto genetic algorithm. Road map hierarchy (2-level) was employed for reducing computing duration. Pareto- and crowding distance-based objective functions were presented in this technique.

$\mathrm{Yu}$ and Lu (2012) developed a VTR system algorithm having mutation and crossover operators redefined in a single mode with two new operators, namely, hyper-mutation and hyper-crossover, developed for mode-to-mode functioning. A novel objective function operating on a $p$-dimensional vector was employed to locate the optimum path. Routes representation was by changing-length chromosomes, and representation of different kinds of transportation modes was by sub-chromosomes.

Dezani et al. (2014) proposed a new genetic-based VTR system that employs Petri-net method as the objective function. This method permits the system to manage the entire street network in real time. Vehicular ad-hoc network (VANET) is employed for capturing real-time data. Cagara et al. (2014) developed another genetic algorithm for enhancing the optimum use of roads by reallocating vehicles along alternative routes. The drawbacks of complex evolutionary operators and comparatively higher computational costs restricted the application of genetic algorithms, even though they detected random types of objectives and constrains in a satisfactory manner. Table 4 presents the computational intelligence-based algorithms for mitigating congestion.

Table 4. Summary of computational intelligence based algorithms for avoiding congestion

\begin{tabular}{|c|c|c|c|c|}
\hline Reference & Algorithm & Principle & Advantages & Disadvantages \\
\hline $\begin{array}{l}\text { Cong et al. } \\
\text { (2013) }\end{array}$ & \multirow{3}{*}{$\begin{array}{l}\text { Ant Colony } \\
\text { Optimization } \\
\text { (ACO) }\end{array}$} & $\begin{array}{l}\text { The Ant Colony Routing method solves the } \\
\text { dynamic traffic routing issue. This } \\
\text { algorithm employs artificial 'ants' for } \\
\text { searching the network, and the consequent } \\
\text { ants assignment identifies the network's } \\
\text { splitting rates. The algorithm functions by } \\
\text { network pruning and forecast control }\end{array}$ & $\begin{array}{l}\text { Good } \\
\text { effectiveness }\end{array}$ & \multirow{2}{*}{$\begin{array}{l}\text { Theoretical analysis } \\
\text { not easy, Probability } \\
\text { distribution varies } \\
\text { iteratively, } \\
\text { convergence time } \\
\text { not certain }\end{array}$} \\
\hline $\begin{array}{l}\text { Jabbarpour } \\
\text { et al. }(2014)\end{array}$ & & $\begin{array}{l}\text { An ACO algorithm was integrated with map } \\
\text { segmenting and the mean speed of travel } \\
\text { forecast for deriving an enhanced } \\
\text { congestion avoiding method. Segmenting } \\
\text { and short-term forecast were utilized for } \\
\text { overcoming the dynamic nature and rapid } \\
\text { variations of road traffic }\end{array}$ & $\begin{array}{l}\text { Performs well in } \\
\text { terms of average } \\
\text { travelling speed } \\
\text { and time even } \\
\text { when usage is } \\
\text { high }\end{array}$ & \\
\hline $\begin{array}{l}\text { Wang et al. } \\
(2015)\end{array}$ & & $\begin{array}{l}\text { The proposed multi-metric ACO algorithm } \\
\text { achieves real-time variable route planning in } \\
\text { complex urban traffic. Attributes are } \\
\text { gathered from real traffic scenarios as the } \\
\text { pheromone values of the ACO algorithm } \\
\text { that can create real-time route plans. Then, } \\
\text { method for order preference by similarity to } \\
\text { ideal solution technique is used in forked } \\
\text { roads for choosing the optimal route }\end{array}$ & $\begin{array}{l}\text { Achieves suitable } \\
\text { routes as per } \\
\text { varied } \\
\text { requirements } \\
\text { easily, good } \\
\text { shortest route and } \\
\text { time planning }\end{array}$ & \\
\hline $\begin{array}{l}\text { Teodorović } \\
\text { and Dell'Orco } \\
(2008)\end{array}$ & \multirow[t]{2}{*}{$\begin{array}{l}\text { Bee-based } \\
\text { optimization }\end{array}$} & $\begin{array}{l}\text { The algorithm provides a solution to the } \\
\text { ride-matching issue, and, as a result, the } \\
\text { congestion issue using BBO. Ride-matching } \\
\text { assists commuters in sharing a transport } \\
\text { during their travel to their destinations, and } \\
\text { thus minimize the number of vehicles } \\
\text { having one occupant only }\end{array}$ & $\begin{array}{l}\text { Effective, simple, } \\
\text { and robust }\end{array}$ & \multirow{2}{*}{$\begin{array}{l}\text { Convergence for } \\
\text { local minima slow, } \\
\text { initialization is } \\
\text { random, parameters } \\
\text { for tuning are more }\end{array}$} \\
\hline $\begin{array}{l}\text { Wedde and } \\
\text { Senge (2007) }\end{array}$ & & $\begin{array}{l}\text { The BeeJam algorithm works on a multi- } \\
\text { agent method, based on the foraging nature } \\
\text { of bees. It has a dispersed vehicular- } \\
\text { infrastructural architecture }\end{array}$ & $\begin{array}{l}\text { Travel times very } \\
\text { much reduced }\end{array}$ & \\
\hline
\end{tabular}




\begin{tabular}{|c|c|c|c|c|}
\hline Reference & Algorithm & Principle & Advantages & Disadvantages \\
\hline $\begin{array}{l}\text { Wen and Gen } \\
(2008)\end{array}$ & \multirow{3}{*}{$\begin{array}{c}\text { Genetic } \\
\text { Algorithm (GA) }\end{array}$} & $\begin{array}{l}\text { An effective selection method was devised } \\
\text { for solving multi-objective route solving } \\
\text { keeping driving distance, time, and cost } \\
\text { minimal, at the same time. A genetic } \\
\text { algorithm termed distance Pareto GA is } \\
\text { proposed for solving the problem. The } \\
\text { solution assures rapid convergence on the } \\
\text { Pareto-optimal front and gives ample } \\
\text { attention to diversity }\end{array}$ & $\begin{array}{l}\text { Can handle } \\
\text { random types of } \\
\text { objectives and } \\
\text { constraints }\end{array}$ & \multirow{3}{*}{$\begin{array}{l}\text { High computation } \\
\text { cost, complex } \\
\text { evolutionary } \\
\text { operators }\end{array}$} \\
\hline $\begin{array}{l}\text { Yu and Lu } \\
(2012)\end{array}$ & & $\begin{array}{l}\text { This enhanced GA for route strategizing in } \\
\text { multi-criteria/multi-modal environment uses } \\
\text { mutation/crossover operators in single mode, } \\
\text { and hyper-mutation/hyper-crossover in inter- } \\
\text { mode functioning. Vector-based assessment } \\
\text { is used for representing multiple criteria. By } \\
\text { multi-objective ranking approach, the } \\
\text { optimum solutions are arrived at }\end{array}$ & $\begin{array}{l}\text { Easy tuning of } \\
\text { parameters }\end{array}$ & \\
\hline $\begin{array}{l}\text { Dezani et al. } \\
(2014)\end{array}$ & & $\begin{array}{l}\text { The methodology uses the Petri net analysis } \\
\text { as the GA's fitness function. The output of } \\
\text { this fitness function is the overall duration } \\
\text { which vehicles take to arrive at their } \\
\text { destinations. An algorithm was developed } \\
\text { that works on the High-level Petri net } \\
\text { analyses for suggesting a vehicle the } \\
\text { optimal route based on travelling time }\end{array}$ & $\begin{array}{l}\text { Fast solutions, no } \\
\text { overload of } \\
\text { roadways }\end{array}$ & \\
\hline
\end{tabular}

\subsection{Accurate prediction of travel time}

In the present times, accurate systems of travel time prediction are strongly required in public transport. In an emergency, such systems help users to reach the nearest location, such as hospitals, schools, and airports, in a minimal amount of time. In addition, people can select the mode of transportation by knowing the travel time. Prediction of travel time can be modeled as historical, datadriven, and model-based. The three different models of travel time prediction discussed in this section are presented in Table 5. The approaches for solving travel time prediction can be broadly classified as parametric, non-parametric, and hybrid solutions.

\section{Approach 1: Parametric approaches}

In the past, predicting the future requirements of traffic was based on analysis of time series by observing historical data. In a time series, a set of observed readings $x$ are captured at a particular time $t$. The aim is to look for temporal patterns in historical traffic information and employ these results for forecasts. Ahmed and Cook (1979) employed the Auto Regressive Integrated Moving Average (ARIMA) approach for predicting short-term traffic, which generated better results over conventional doubleexponential smoothening and moving average approaches. Also, Hamed et al. (1995) conducted a timeseries study using the Box-Jenkins approach for forecasting short-term traffic flow and suggested that the ARIMA method was forecasted traffic flow accurately for urban arterial streets. Following this, Williams and Hoel (2003) proposed seasonal ARIMA, Van Der Voort et al. (1996) developed the Kohenen ARIMA, and Williams (2001) proposed ARIMA combined with an descriptive variable for more accurate prediction of traffic flow. Ghosh et al. (2009) came up with a multivariate structural time-series approach for forecasting traffic volumes. Predicting future traffic flow based on historical data helps to synchronize traffic signals to ensure the smooth flow of the overall traffic of the city. Liu and Wang (2010) proposed a dynamic router travel time prediction approach, which was a model based on historical and current travel time. The traffic pattern is analyzed by extrapolating the present real-time data through closely matched historical patterns.

The Kalman Filtering method for time-series analysis was yet another model applied to the mobile stochastic problems which could solve regression issues and reduce variance for arriving at optimal results. Okutani and Stephanedes (1984), Xie et al. (2007), and Wang et al. (2008), among others used this method for predicting traffic flow.

\section{Approach 2: Non-parametric approaches}

\section{Random Forest Algorithm}

$\mathrm{Yu}$ et al. (2018) proposed a technique called Random Forest based on Near Neighbor (RFNN). RFNN method was calibrated and validated with real-world data, such as location and time, extracted from GPS. The bus travel time between adjacent bus stops was calculated based on real-world data, which was also used to train the RFNN model. In comparison to Linear Regression (LR), KNN, SVM and 
Random Forest (RF), the RFNN model resulted in higher accuracy; however, it required longer computation time. Lack of optimization due to the utilization of parallel computing technology proved to be a drawback of RFNN method. Further, Gupta et al. (2018) proposed an ensemble learning approach to predict taxi travel time. A lot of information was investigated and large features were extracted from the database. Gradient boosting as well as random forest algorithm was used to train and evaluate the performance. Data, such as taxi demand, time, trip length distribution, and most traversed areas, were the points of interest. Statistically, it is observed that gradient boosting method provides better prediction efficiency when compared to the random forest. Random forest response is faster and it is likely to achieve greater accuracy with the increase in training data size. Lack of real time data restricted the scope of outcomes.

\section{Bayesian Algorithm approach}

Development of various prediction models based on certain algorithms is also used in predicting the travel time. Lee et al. (2008) proposed a prediction model based on Naive Bayesian Classification (NBC). The findings revealed that the proposed prediction model yielded higher accuracy and speed when applied to such cases and large dataset. The NBC-based model was scalable to any arbitrary travel route. However, the data collection was not real time and hence the prediction accuracy was reduced. Further, Hamner (2010) prepared a model, based on a context-dependent random forest method, for the prediction of future travel time of cars in selected roads. Features representing local and aggregate traffic flow were extracted to train the model. The collected data included the status of cars, such as the number of stationary and moving cars in different routes. Although the algorithm performed better, it was believed that the technique could be improved by using an advanced model of local traffic flow.

\section{KNN, PCA, and Support Vector Algorithms}

The communication of information between vehicle and infrastructure is another technique to predict the travel time, which helps to determine the density and volume of the traffic. Jenelius and Koutsopoulos (2017) suggested a probe data-based technique to predict urban network travel time. Future travel time is calculated based on the current travel time and network details. This technique divides the network into different sub-networks and applies Probabilistic Principal Component Analysis (PPCA) to each network. In each network, average travel time is modelled as a function of day of the week, time of the day and link. The suggested model has the ability to handle missing data and it is designed considering several components, such as efficiency, flexibility, and robustness. Four months data was taken from the Shenzhen Urban Transport Planning Centre, China, for conducting the research. The results demonstrated that PPCA prediction outperformed KNN prediction with a high accuracy. Tian (2018) proposed a model to predict travel time based on ANN and Support Vector Machine (SVM) under the IoV environment. The results revealed that the least square SVM machine travel time predictor model performed satisfactorily. However, it was only used for short travel time prediction with a limited sample space. Further, Philip et al. (2018) suggested that a data-driven approach renders a better accuracy for travel time when there is a high variability and lesser availability of traffic data. In order to predict urban travel time, data was collected for 11 weeks, covering $2.8 \mathrm{~km}$ via Bluetooth sensors placed at certain locations on an urban arterial corridor in Chennai, India. Support Vector Regression (SVR) model was used in the data-driven approach. The results showed a better performance when compared with ANN. However, Oh et al. (2018) pointed out certain drawbacks, such as the data-driven approach was specific to the location and was therefore subject to change of parameters associated with the location. These drawbacks made the data-driven approach less robust with geometric changes.

\section{Deep Learning Algorithm}

Artificial Neural Networks (ANNs): ANNs are effective methods for modeling traffic data mathematically. They offer functionalities like learning and organizing on their own, and can recognize patterns. They carry out non-linear approximating between outputs and inputs. As they are nonparametric, no assumptions are made regarding data distribution. Smith et al. (1994), Elleuch et al. (2016), and Padiath et al. (2009) proposed solutions based on ANN. Elleuch et al. (2016) proposed an architecture of an intelligent congestion prediction approach based on data fusing and ANN. The approach considered both, the real time unforeseen occurrences which influence traffic jams (e.g. accidents) and the historical GPS information. Padiath et al. (2009) experimented using a historic approach, an ANN-based approach, and a model-based approach to predict traffic density on Indian roads. These were corroborated using data gathered using a video graphic method. A comparison with actual data obtained by input-output analysis indicated that the approaches worked well. Jordan's 
sequential network is an Artificial Neural Network (ANN) technique proposed by More et al. (2016) for predicting road traffic. Traffic volume is used as a prediction parameter. The ANN technique considers real traffic data as well as aggregated past values for predicting the future traffic flow. The performance of the network is analyzed through parameters, such as accuracy and speed. The study revealed that prediction based on both real-time traffic and historical data was found to be more accurate than the prediction based on only historical data.

Multilayer Perceptron (MLP): The MLP consists of several connected neurons which are organized as hierarchical layers, and have an activation function of real values. MLP carries out two important computations: forward and backward passes. In the former, a training data set is introduced in the network and according to the model, the output error is calculated, while in the latter, the calculated error adjusts network weights. Zargari et al. (2012) used MLP algorithm for traffic flow predictions in the Rasht-Quazvin (Iran) highway. For training, Quasi-Newton BP method was used. Hou et al. (2015) used Multi Layer Feed-forward network for predicting traffic flow using sensors for data acquisition in workzone freeways in St. Louis (US). Xu et al. (2017) employed Random Forest and MLP algorithm for predicting traffic flow. Toll information was used as the data source in an expressway. Pamula (2018) used a combined MLP/Autoencoder algorithm for predicting traffic flow in an urban road in Gliwice (Germany). The Levenberg-Marquardt algorithm was used for training. Another variation of the MLP is the Back Propagation Neural Network (BPNN). Xu et al. (2018) used BPNN technique for trip-oriented travel time prediction for urban networks, based on historical vehicle trajectories. The results indicated the daily and weekly variations of travel time, and the impact of climatic conditions on it. The findings also revealed that the predictions were largely impacted by non-trivial conditions. The study pointed out that the prediction based on available historical data was intriguing due to spatial and temporal correlations, changes in weather conditions, and some random unknown factors, which lead to abrupt variations in the travel time. These factors limit the application of BPNN technique in predicting the travel time of vehicles.

Convolution Neural Network (CNN): The CNN neurons are connected to a smaller group of inputs (compared to ANN), which reduces the total variables in the network. Further, CNNs are able to extract significant and distinctive image features by using the convolution function. Yu et al. (2017) used CNN as the prediction algorithm for traffic flow in a highway in Beijing. Adam optimization algorithm was used for training. Liao et al. (2018) used CNN for predicting traffic flow in a freeway in California. The training was carried out using Supervised Stochastic Gradient Descent algorithm. Chung et al. (2018) used Deep CNN for predicting density of traffic and Gradient Descent Back-propagation algorithm for training. Video detectors were used to gather data. Zhang et al. (2019) used CNN for predicting traffic flow in a roadway in New York City.

Recurrent Neural Networks (RNNs): Typical ANNs cannot work with sequential and time series information since they do not have a memory feature. However, RNNs can handle sequences and time series data, along with temporal-spatial issues. An et al. (2011) used the RNN algorithm for predicting traffic flow in an urban arterial road in Xian (China) and the least square algorithm for training.

Long Short Term Memory Networks (LSTMs): LSTM is a variant of RNN and is better than RNN since it selectively remembers patterns for a longer duration. The network can work with time series information in the short term and the long term. Ma et al. (2015a), Shao and Soong (2016), and Zhao et al. (2017) used LSTM for predicting traffic flow, speed, Vehicle volume, Lane occupancy, and Average velocity in freeways in Beijing. They used RTMS detector, video detector, and cameras, respectively, as data sources. Kang et al. (2017), again, used LSTM for predicting traffic flow and Adam optimizer algorithm for training. Liu et al. (2017) suggested similarities in the flow of traffic with respect to its time series. They reported that these time series were affected by external factors, such as traffic accidents, roadwork, fluctuations in traffic demand, and change in weather. This resulted in non-stationary properties of the prediction algorithm. Under such conditions, the authors proposed a deep learning approach along with time series to obtain reliable and accurate prediction. The study was conducted by testing and using Long Short-Term Memory with Deep Neural Networks (LSTM-DNN) model. The study pointed out that one-step prediction accuracy was found to be greater in short-term time series.

Stacked LSTM: Here, multiple LSTM layers are stacked forming a deep LSTM-driven neural network having the following advantages: (i) it permits the model to learn features of raw temporal data from varied facets at every time stage and (ii) model variables are distributed throughout the entire model space without enhancing memory, thereby enabling the model to hasten convergence. Abbas et al. (2018) employed stacked LSTM algorithm for predicting traffic flow, density, congestion, and speed using motorway control system data in a highway near Stockholm. Zou et al. (2018) also used stacked LSTM algorithm for predicting traffic flow in a freeway in New York City. They used GPS data from BikeNYC. 
Gated Recurrent Unit (GRU): The LSTM network has an issue of vanishing gradient. To overcome this issue, the GRU has been developed without a distinct memory block, thereby making it more efficient and easy to use during training. Zhang and Kabuka (2018) used a GRU for predicting traffic flow based on Caltrans PeMS sensor data from highways in California. Fu et al. (2016) used LSTM and Gated Recurrent Unit algorithm for traffic flow prediction in a freeway and Back-propagation Through Time algorithm for training.

Wavelet Neural Network (WNN): The WNN approach searches a wavelet group in feature space in a manner that the intricate relationship inside the original signal would be represented. They were developed as mechanisms for approximating functions which enables solving poor convergence problems of conventional neural networks. Guorong and Yanping (2010), Gao et al. (2013), and Li et al. (2014) used WNN algorithm for predicting traffic flow in urban areas in China.

Stacked Autoencoder (SAE): Here, multiple autoencoders are stacked in many concealed layers above one another by employing a layer-wise learning algorithm. All autoencoders take bottleneck activating output vectors as their inputs from the autoencoder layers below them. After the concealed layers of stacked autoencoders are trained, a back-propagation method reduces the error function by weights updating. Duan et al. (2016) and Yang et al. (2017) used SAE algorithm for prediction of traffic flow in freeways. Further, a regression layer was used on top of the SAE layer.

Deep Belief Network (DBN): DBNs are comprised of at least one stacked Restricted Boltzmann Machine (RBM) layer for the pre-training stage after which a feed-forward algorithm fine tunes it. Concealed layers collect relevant features from the inputs which are forwarded as inputs to the subsequent RBM layer that is stacked on it, thus creating a deterministic neural network. Huang et al. (2014) and Soua et al. (2016) proposed a method for predicting traffic flow using DBN on freeways using Greedy layerwise unsupervised learning and supervised back-propagation, respectively, for training. Zhang et al. (2018) proposed a method for prediction of traffic flow using DBN and Genetic Algorithm and FletcherReeves conjugate gradient algorithm for training.

\section{Approach 3: Hybrid approaches}

As traffic flow information is non-linear and complex, it becomes difficult to predict results accurately using only a single model. Therefore, hybrid modelling methods for improved prediction results are necessary. These approaches predict traffic flow employing a combination of multiple intelligent models for improved accuracy. Wu and Tan (2016) combined CNN and LSTM algorithms for prediction of traffic flow on a freeway. Ma et al. (2015b) used a deep learning approach for a large-scale transport network employing GPS data. RBM and RNN models driven by gradient descent optimizing approach were used. The training data was separated into several mini samples, with all sets being operated in parallel employing conventional gradient descent optimizing approach. Table 5 provides a summary of the discussed methods.

Table 5. Summary of Travel Time Prediction Techniques

\begin{tabular}{|c|c|c|c|c|}
\hline Types & Authors & $\begin{array}{l}\text { Prediction } \\
\text { Techniques }\end{array}$ & Advantages & Disadvantages \\
\hline \multirow[t]{2}{*}{$\begin{array}{l}\text { Parametric } \\
\text { approaches }\end{array}$} & $\begin{array}{l}\text { Ahmed and Cook (1979), Hamed et al. } \\
\text { (1995), Williams and Hoel (2003), Van Der } \\
\text { Voort et al. (1996), Williams (2001), Ghosh } \\
\text { et al. (2009) }\end{array}$ & Time series & $\begin{array}{l}\text {-Ease of use } \\
\text {-Minimal } \\
\text { computations } \\
\text { required }\end{array}$ & $\begin{array}{l}\text {-Models based on static } \\
\text { framework } \\
\text {-New observations not } \\
\text { used to update model } \\
\end{array}$ \\
\hline & $\begin{array}{l}\text { Okutani and Stephanedes (1984), Xie et al. } \\
\text { (2007), Wang et al. (2008) }\end{array}$ & Kalman Filtering & $\begin{array}{l}\text { Allows state } \\
\text { variables } \\
\text { updating } \\
\text { without } \\
\text { interruption } \\
\end{array}$ & $\begin{array}{l}\text {-Can generate over- or } \\
\text { under-prediction } \\
\text {-Cannot handle } \\
\text { unstable traffic } \\
\text { conditions }\end{array}$ \\
\hline \multirow[t]{4}{*}{$\begin{array}{l}\text { Non- } \\
\text { parametric } \\
\text { approaches }\end{array}$} & Yu et al. (2018), Gupta et al. (2018) & Random Forest & $\begin{array}{l}\text {-Easy } \\
\text { implementation } \\
\text {-Training speed } \\
\text { is fast }\end{array}$ & $\begin{array}{l}\text {-Cannot predict beyond } \\
\text { the range in the } \\
\text { training data } \\
\text {-Overfitting issues }\end{array}$ \\
\hline & Lee et al. (2008), Hamner (2010) & $\begin{array}{l}\text { Bayesian } \\
\text { approach }\end{array}$ & $\begin{array}{l}\text { Can update } \\
\text { prediction when } \\
\text { new information } \\
\text { is available }\end{array}$ & $\begin{array}{l}\text {-Higher computational } \\
\text { cost }\end{array}$ \\
\hline & $\begin{array}{l}\text { Jenelius and Koutsopoulos (2017), Tian } \\
\text { (2018), Philip et al. (2018), Oh et al. (2018) }\end{array}$ & $\begin{array}{l}\text { KNN, PCA, and } \\
\text { Support Vector }\end{array}$ & $\begin{array}{l}\text {-Robust to noise } \\
\text {-Fast }\end{array}$ & $\begin{array}{l}\text { Spatial and temporal } \\
\text { modeling cannot be } \\
\text { handled together }\end{array}$ \\
\hline & $\begin{array}{l}\text { Smith et al. (1994), Elleuch et al. (2016), } \\
\text { Padiath et al. (2009), More et al. (2016) }\end{array}$ & $\begin{array}{l}\text { Deep Learning: } \\
\text { ANN }\end{array}$ & $\begin{array}{l}\text { Handles non- } \\
\text { linear } \\
\text { approximation }\end{array}$ & $\begin{array}{l}\text { Handles complex } \\
\text { problems poorly }\end{array}$ \\
\hline
\end{tabular}




\begin{tabular}{|c|c|c|c|c|}
\hline & $\begin{array}{l}\text { Zargari et al. (2012), Hou et al. (2015), Xu } \\
\text { et al. (2017), Pamula (2018) }\end{array}$ & $\begin{array}{l}\text { Deep Learning: } \\
\text { MLP }\end{array}$ & Can self learn & $\begin{array}{l}\text { Cannot handle time- } \\
\text { series data }\end{array}$ \\
\hline & $\begin{array}{l}\text { Yu et al. (2017), Liao et al. (2018), Chung et } \\
\text { al. (2018), Zhang et al. (2019) }\end{array}$ & $\begin{array}{l}\text { Deep Learning: } \\
\text { CNN }\end{array}$ & $\begin{array}{l}\text { Can recognize } \\
\text { images well }\end{array}$ & $\begin{array}{l}\text { More training data } \\
\text { required for predicting }\end{array}$ \\
\hline & An et al. (2011) & $\begin{array}{l}\text { Deep Learning: } \\
\text { RNN }\end{array}$ & $\begin{array}{l}\text { Can handle } \\
\text { dynamic issues }\end{array}$ & $\begin{array}{l}\text { Multiple parameters } \\
\text { needed for updating }\end{array}$ \\
\hline & $\begin{array}{l}\text { Ma et al. (2015a), Shao and Soong (2016), } \\
\text { Zhao et al. (2017), Kang et al. (2017), Liu et } \\
\text { al. (2017), Abbas et al. (2018), Zou et al. } \\
(2018)\end{array}$ & $\begin{array}{l}\text { Deep Learning: } \\
\text { LSTM }\end{array}$ & $\begin{array}{l}\text { Can selectively } \\
\text { remember } \\
\text { patterns for } \\
\text { longer duration }\end{array}$ & $\begin{array}{l}\text { Cumbersome training } \\
\text { needed }\end{array}$ \\
\hline & Zhang and Kabuka (2018), Fu et al. (2016) & $\begin{array}{l}\text { Deep Learning: } \\
\text { GRU }\end{array}$ & Easy to train & $\begin{array}{l}\text { Slow convergence and } \\
\text { low learning efficiency }\end{array}$ \\
\hline & $\begin{array}{l}\text { Guorong and Yanping (2010), Gao et al. } \\
\text { (2013), Li et al. (2014) }\end{array}$ & $\begin{array}{l}\text { Deep Learning: } \\
\text { WNN }\end{array}$ & $\begin{array}{l}\text { Can handle non- } \\
\text { linear and } \\
\text { complex } \\
\text { highway traffic } \\
\text { flow data }\end{array}$ & $\begin{array}{l}\text { Lacks basis parameter } \\
\text { selection }\end{array}$ \\
\hline & Duan et al. (2016), Yang et al. (2017) & $\begin{array}{l}\text { Deep Learning: } \\
\text { SAE }\end{array}$ & $\begin{array}{l}\text { Accurate feature } \\
\text { extraction }\end{array}$ & Time consuming \\
\hline & $\begin{array}{l}\text { Huang et al. (2014), Soua et al. (2016), } \\
\text { Zhang et al. (2018) }\end{array}$ & $\begin{array}{l}\text { Deep Learning: } \\
\text { DBN }\end{array}$ & $\begin{array}{l}\text { Robust } \\
\text { classification }\end{array}$ & $\begin{array}{l}\text { Training is } \\
\text { complicated }\end{array}$ \\
\hline $\begin{array}{l}\text { Hybrid } \\
\text { approaches }\end{array}$ & Ma et al. (2015b), Wu and Tan (2016) & $\begin{array}{l}\text { RNN and } \\
\text { Restricted } \\
\text { Boltzmann } \\
\text { Machine } \\
\end{array}$ & $\begin{array}{l}\text { Can handle } \\
\text { multiple } \\
\text { parameters for } \\
\text { updating }\end{array}$ & $\begin{array}{l}\text { Noise (weather, state } \\
\text { of the roads) affects the } \\
\text { model }\end{array}$ \\
\hline
\end{tabular}

\section{Conclusions and future work}

The present paper conducted a literature survey to identify the efficiencies of key existing Intelligent Transportation Systems (ITS) for managing traffic. The paper reviewed studies that examined the performance of ITS based on its functional efficiencies. The review revealed that ITS used wireless network systems to gather the data about vehicles and performed significantly well in comparison with other data collection techniques. However, high expense of antennas limits its application. Further, various studies with different technologies in managing traffic and indicated that the application of a specific technique relies on the nature of location, where the traffic needs to be managed. The review of studies pertaining to the application of different technologies in managing traffic revealed that the application of deep learning technologies and certain optimization algorithms like Ant and Bee algorithms provided better results in managing traffic. The review of various technologies used for predicting accurate travel time through the detection of traffic congestion signposted that technologies designed on two models provide a better accuracy in the detection of vehicular congestions, thereby predicting travel time with a high degree of accuracy.

Thus, in conclusion, this survey on using ITS for reducing traffic congestion indicates that ITS options are vast, involve several technologies, and have the potential to mitigate most of the traffic problems. However, the application should rely on the nature of location, where the traffic needs to be managed. If appropriate ITS is used according to the nature of location, then travel time and queues could be reduced, resulting in the provision of better safety and productivity. In addition to these findings, the review pointed out certain unexplored areas, which open the door for future researchers. These future directions are described in the subsequent subsection.

\section{Future directions}

\section{- Improvement in data collection}

Owing to the constant mobility of vehicles, the collected data might often not be accurate, complete, or dependable. Research on the techniques that yield better quality of data would be significant. In the era of Internet of Things, many new upcoming sensing methods could help in the improvement of data acquisition and quality. Additionally, research on the adoption of automatic data-capturing techniques that reduce manual data entry can benefit data quality improvement.

\section{- Integration of non-homogeneous data sources}

Lately, there has been a proliferation of devices, each with its own standards. Traffic management systems need to work with all such devices. Therefore, developing common standards is a challenge, which needs a considerable collaborative research. 


\section{- Managing huge amounts of data}

Data is reaching massive proportions with the growth of Internet of Things. The seamless integration and processing of data is another big challenge, and much research is needed for managing the data. The use of technologies, such as cloud computing and edge computing, could be considered. Using Big Data technology to gather traffic data of an entire city, practical data can be provided for guiding traffic and urban planning, which could solve problems related to traffic congestion analysis, traffic flow prediction, and wise planning of transportation infrastructure (Wang et al., 2018).

\section{- Privacy concerns}

Huge amount of data stored via latest technologies could contain the private data of the respective owners. The transmission of such sensitive information could be intercepted by hackers. Therefore, the ensuring of safe traffic management systems is a challenge that requires further research.

\section{- Detection of traffic hazards}

Even though the techniques for identification of traffic hazards have been studied, they are not efficient enough. Potential hazards must be correctly identified and transmitted to the drivers for them to take appropriate action. The area of detecting traffic hazards still needs to be researched.

\section{- Policy formulations}

Parameters like traffic violations and accidents need to be integrated with traffic managing systems in the future so that policy makers can use such data while framing traffic rules. Research on how to integrate such data will prevent avoidable mishaps.

\section{References}

1. Abbas, Z., Al-Shishtawy, A., Girdzijauskas, S., Vlassov, V. (2018) Short-term traffic prediction using long short-term memory neural networks. In: 2018 IEEE International Congress on Big Data (BigData Congress), 57-65.

2. Ahmad, F., Basit, A., Ahmad, H., Mahmud, S. A., Khan, G. M., \& Yousaf, F. Z. (2013) Feasibility of deploying wireless sensor based road side solutions for intelligent transportation systems. In: 2013 International Conference on Connected Vehicles and Expo (ICCVE), 320-326.

3. Ahmed, M.S., Cook, A.R. (1979) Analysis of freeway traffic time-series data by using Box-Jenkins techniques, No. 722.

4. An, Y., Song, Q. and Zhao, X. (2011) Short-term traffic flow forecasting via echo state neural networks. In 2011 Seventh International Conference on Natural Computation, 2, 844-847.

5. Araújo, G. B., Queiroz, M. M., de LP Duarte-Figueiredo, F., Tostes, A. I., \& Loureiro, A. A. (2014). Cartim: A proposal toward identification and minimization of vehicular traffic congestion for vanet. In: 2014 IEEE symposium on computers and communications (ISCC), 1-6.

6. Avatefipour, O., Sadry, F. (2018) Traffic management system using IoT technology-A comparative review. In: 2018 IEEE International Conference on Electro/Information Technology (EIT), 1041-1047.

7. Barros, J., Araujo, M., Rossetti, R. J. (2015) Short-term real-time traffic prediction methods: A survey. In: 2015 International Conference on Models and Technologies for Intelligent Transportation Systems (MT-ITS), 132-139.

8. Bell, M. G., Trozzi, V., Hosseinloo, S. H., Gentile, G., \& Fonzone, A. (2012) Time-dependent Hyperstar algorithm for robust vehicle navigation. Transportation Research Part A: Policy and Practice, 46(5), 790-800.

9. Bernas, M., Płaczek, B., \& Korski, W. (2018) Wireless Network with Bluetooth Low Energy Beacons for Vehicle Detection and Classification. In: International Conference on Computer Networks, 429-444. Springer, Cham.

10. Bruno, R., \& Nurchis, M. (2013) Robust and efficient data collection schemes for vehicular multimedia sensor networks. In: 2013 IEEE 14th International Symposium on" A World of Wireless, Mobile and Multimedia Networks" (WoWMoM), 1-10. IEEE.

11. Cagara, D., Bazzan, A. L., \& Scheuermann, B. (2014) Getting you faster to work: A genetic algorithm approach to the traffic assignment problem. In: Proceedings of the Companion Publication of the 2014 Annual Conference on Genetic and Evolutionary Computation, 105-106. ACM. 
12. Chao, K. H., \& Chen, P. Y. (2014) An intelligent traffic flow control system based on radio frequency identification and wireless sensor networks. International journal of distributed sensor networks, 10(5), 694545.

13. Chen, C. P., Zhou, J., \& Zhao, W. (2012) A real-time vehicle navigation algorithm in sensor network environments. IEEE Transactions on Intelligent Transportation Systems, 13(4), 1657-1666.

14. Chen, X., Chen, R. (2019) A Review on Traffic Prediction Methods for Intelligent Transportation System in Smart Cities. In: 2019 12th International Congress on Image and Signal Processing, BioMedical Engineering and Informatics (CISP-BMEI), 1-5. IEEE.

15. Chhatpar, P., Doolani, N., Shahani, S., Priya, R.L. (2018) Machine learning solutions to vehicular traffic congestion. In: 2018 International Conference on Smart City and Emerging Technology (ICSCET), 1-4. IEEE.

16. Choi, O., Kim, S., Jeong, J., Lee, H. W., \& Chong, S. (2015) Delay-optimal data forwarding in vehicular sensor networks. IEEE transactions on vehicular technology, 65(8), 6389-6402.

17. Chowdhury, M., Hasan, M., Safait, S. (2018) A novel approach to forecast traffic congestion using CMTF and machine learning (Doctoral dissertation, BRAC University).

18. Chung, J., \& Sohn, K. (2018) Image-Based Learning to Measure Traffic Density Using a Deep Convolutional Neural Network. IEEE Transactions on Intelligent Transportation Systems, 19(5), 1670-1675.

19. Collotta, M., Pau, G., Scatà, G., \& Campisi, T. (2014) A dynamic traffic light management system based on wireless sensor networks for the reduction of the red-light running phenomenon. Transport and Telecommunication, 15(1), 1-11.

20. Cong, Z., De Schutter, B., \& Babuška, R. (2013) Ant colony routing algorithm for freeway networks. Transportation Research Part C: Emerging Technologies, 37, 1-19.

21. Cordeschi, N., Amendola, D., Shojafar, M., Naranjo, P. G. V., \& Baccarelli, E. (2015). Memory and memoryless optimal time-window controllers for secondary users in vehicular networks. In: Proceedings of the International Symposium on Performance Evaluation of Computer and Telecommunication Systems, 1-7. Society for Computer Simulation International.

22. de Souza, A. M., Yokoyama, R. S., Botega, L. C., Meneguette, R. I., \& Villas, L. A. (2015) Scorpion: A solution using cooperative rerouting to prevent congestion and improve traffic condition. In: 2015 IEEE International Conference on Computer and Information Technology; Ubiquitous Computing and Communications; Dependable, Autonomic and Secure Computing; Pervasive Intelligence and Computing, 497-503. IEEE.

23. de Souza, A. M., Yokoyama, R. S., Maia, G., Loureiro, A., \& Villas, L. (2016) Real-time path planning to prevent traffic jam through an intelligent transportation system. In: 2016 IEEE Symposium on Computers and Communication (ISCC), 726-731. IEEE.

24. de Souza, A. M., Brennand, C. A., Yokoyama, R. S., Donato, E. A., Madeira, E. R., Villas, L. A. (2017) Traffic management systems: A classification, review, challenges, and future perspectives. International Journal of Distributed Sensor Networks, 13(4), p.1550147716683612.

25. Dezani, H., Bassi, R. D., Marranghello, N., Gomes, L., Damiani, F., \& Da Silva, I. N. (2014) Optimizing urban traffic flow using Genetic Algorithm with Petri net analysis as fitness function. Neurocomputing, 124, 162-167.

26. Duan, Y., Lv, Y. and Wang, F.Y. (2016) Performance evaluation of the deep learning approach for traffic flow prediction at different times. In: 2016 IEEE International Conference on Service Operations and Logistics, and Informatics (SOLI), 223-227. IEEE.

27. Elleuch, W., Wali, A. and Alimi, A.M. (2016) Intelligent Traffic Congestion Prediction System Based on ANN and Decision Tree Using Big GPS Traces. In: International conference on intelligent systems design and applications, 478-487. Springer, Cham.

28. Emo, A. K., Matthews, G., \& Funke, G. J. (2016) The slow and the furious: Anger, stress and risky passing in simulated traffic congestion. Transportation research part $F$ : traffic psychology and behaviour, 42, 1-14.

29. Fan, S. K. S., Su, C. J., Nien, H. T., Tsai, P. F., \& Cheng, C. Y. (2018) Using machine learning and big data approaches to predict travel time based on historical and real-time data from Taiwan electronic toll collection. Soft Computing, 22(17), 5707-5718.

30. Faye, S., Chaudet, C., \& Demeure, I. (2012) A distributed algorithm for adaptive traffic lights control. In: 2012 15th International IEEE Conference on Intelligent Transportation Systems, 1572-1577. IEEE.

31. Friesen, M., Jacob, R., Grestoni, P., Mailey, T., Friesen, M. R., \& McLeod, R. D. (2014) Vehicular traffic monitoring using bluetooth scanning over a wireless sensor network. Canadian Journal of Electrical and Computer Engineering, 37(3), 135-144. 
32. Fu, R., Zhang, Z. and Li, L. (2016) November. Using LSTM and GRU neural network methods for traffic flow prediction. In: 2016 31st Youth Academic Annual Conference of Chinese Association of Automation (YAC), 324-328. IEEE.

33. Gao, J., Leng, Z., Qin, Y., Ma, Z., Liu, X. (2013) Short-term traffic flow forecasting model based on wavelet neural network. In: 2013 25th Chinese control and decision conference (CCDC), 5081-5084. IEEE.

34. Ghosh, B., Basu, B., O'Mahony, M. (2009) Multivariate short-term traffic flow forecasting using time-series analysis. IEEE transactions on intelligent transportation systems, 10(2), 246-254.

35. Ghosh, R.; Akula, A.; Kumar, S.; Sardana, H. (2015) Time-frequency analysis based robust vehicle detection using seismic sensor. J. Sound Vibr., 346, 424-434.

36. Guo, F., Polak, J.W., Krishnan, R. (2010) Comparison of modelling approaches for short term traffic prediction under normal and abnormal conditions. In: 13th International IEEE Conference on Intelligent Transportation Systems, 1209-1214. IEEE.

37. Guorong, G., Yanping, L. (2010) Traffic flow forecasting based on PCA and wavelet neural network. In: 2010 International Conference of Information Science and Management Engineering, 1, 158-161. IEEE.

38. Gupta, B., Awasthi, S., Gupta, R., Ram, L., Kumar, P., Prasad, B. R., \& Agarwal, S. (2018) Taxi travel time prediction using ensemble-based random forest and gradient boosting model. In: Advances in Big Data and Cloud Computing, 63-78. Springer, Singapore.

39. Haferkamp, M., Al-Askary, M., Dorn, D., Sliwa, B., Habel, L., Schreckenberg, M., \& Wietfeld, C. (2017) Radio-based traffic flow detection and vehicle classification for future smart cities. In: 2017 IEEE 85th Vehicular Technology Conference (VTC Spring), 1-5. IEEE.

40. Hamed, M.M., Al-Masaeid, H.R., Said, Z.M.B. (1995) Short-term prediction of traffic volume in urban arterials. Journal of Transportation Engineering, 121(3), 249-254.

41. Hamner, B. (2010) Predicting travel times with context-dependent random forests by modeling local and aggregate traffic flow. In: 2010 IEEE International Conference on Data Mining Workshops, 1357-1359. IEEE.

42. Hong, W.C. (2011) Traffic flow forecasting by seasonal SVR with chaotic simulated annealing algorithm. Neurocomputing, 74(12-13), 2096-2107.

43. Hou, Y., Edara, P., Sun, C. (2014) Traffic flow forecasting for urban work zones. IEEE transactions on intelligent transportation systems, 16(4), 1761-1770.

44. Huang, W., Song, G., Hong, H., Xie, K. (2014) Deep architecture for traffic flow prediction: deep belief networks with multitask learning. IEEE Transactions on Intelligent Transportation Systems, 15(5), 2191-2201.

45. Jabbarpour, M. R., Jalooli, A., Shaghaghi, E., Noor, R. M., Rothkrantz, L., Khokhar, R. H., \& Anuar, N. B. (2014) Ant-based vehicle congestion avoidance system using vehicular networks. Engineering Applications of Artificial Intelligence, 36, 303-319.

46. Jenelius, E., \& Koutsopoulos, H. N. (2017) Urban network travel time prediction based on a probabilistic principal component analysis model of probe data. IEEE Transactions on Intelligent Transportation Systems, 19(2), 436-445.

47. Kang, D., Lv, Y., Chen, Y.Y. (2017) Short-term traffic flow prediction with LSTM recurrent neural network. In: 2017 IEEE 20th International Conference on Intelligent Transportation Systems (ITSC), 1-6. IEEE.

48. Ke, R., Li, Z., Kim, S., Ash, J., Cui, Z., \& Wang, Y. (2017) Real-Time Bidirectional Traffic Flow Parameter Estimation From Aerial Videos. IEEE Transactions on Intelligent Transportation Systems, 18(4), 890-901.

49. Khan, N. A. (2017) Real time predictive monitoring system for urban transport (Doctoral dissertation, Kingston University).

50. Lee, H., Chowdhury, N. K., \& Chang, J. (2008) A new travel time prediction method for intelligent transportation systems. In: International Conference on Knowledge-Based and Intelligent Information and Engineering Systems, 473-483. Springer, Berlin, Heidelberg.

51. Li, D.M., Liu, B.I.N. (2014) Modeling and prediction of highway traffic flow based on wavelet neural network. In: 2014 International Conference on Machine Learning and Cybernetics, 2, 675-679. IEEE.

52. Liang, Z., Wakahara, Y. (2013) City traffic prediction based on real-time traffic information for intelligent transport systems. In: 2013 13th International Conference on ITS Telecommunications (ITST), 378-383. IEEE. 
53. Liao, S., Chen, J., Hou, J., Xiong, Q., Wen, J. (2018) Deep convolutional neural networks with random subspace learning for short-term traffic flow prediction with incomplete data. In: 2018 International Joint Conference on Neural Networks (IJCNN), 1-6. IEEE.

54. Liu, W., \& Wang, Z. (2010) Dynamic router real-time travel time prediction based on a road network. In: International Symposium on Information and Automation, 723-729. Springer, Berlin, Heidelberg.

55. Liu, Y., \& Li, S. (2011) A vehicle-logo location approach based on edge detection and projection. In: Proceedings of 2011 IEEE International Conference on Vehicular Electronics and Safety, 165-168. IEEE.

56. Liu, Y., Wang, Y., Yang, X., \& Zhang, L. (2017). Short-term travel time prediction by deep learning: A comparison of different LSTM-DNN models. In: 2017 IEEE 20th International Conference on Intelligent Transportation Systems (ITSC), 1-8. IEEE.

57. Ma, X., Dai, Z., He, Z., Ma, J., Wang, Y., Wang, Y. (2017) Learning traffic as images: a deep convolutional neural network for large-scale transportation network speed prediction. Sensors, 17(4), 818.

58. Ma, X., Tao, Z., Wang, Y., Yu, H., Wang, Y. (2015a) Long short-term memory neural network for traffic speed prediction using remote microwave sensor data. Transportation Research Part C: Emerging Technologies, 54, 187-197.

59. Ma, X., Yu, H., Wang, Y., Wang, Y. (2015b) Large-scale transportation network congestion evolution prediction using deep learning theory. PloS one, 10(3), p.e0119044.

60. Meneguette, R. I., Geraldo Filho, P. R., Bittencourt, L. F., Ueyama, J., Krishnamachari, B., \& Villas, L. A. (2015) Enhancing intelligence in inter-vehicle communications to detect and reduce congestion in urban centers. In: 2015 IEEE Symposium on Computers and Communication (ISCC), 1-6. IEEE.

61. Min, W., \& Wynter, L. (2011) Real-time road traffic prediction with spatio-temporal correlations. Transportation Research Part C: Emerging Technologies, 19(4), 606-616.

62. Mohan, P., Padmanabhan, V.N., \& Ramjee, R. (2008) Nericell: rich monitoring of road and traffic conditions using mobile smartphones. In: Proceedings of the 6th ACM conference on Embedded network sensor systems, 323-336. ACM.

63. More, R., Mugal, A., Rajgure, S., Adhao, R.B., \& Pachghare, V.K. (2016) Road traffic prediction and congestion control using Artificial Neural Networks. In: 2016 International Conference on Computing, Analytics and Security Trends (CAST), 52-57. IEEE.

64. MTTM Movement-Travel Times Methodology (2018) URL: https://d3i4yxtzktqr9n.cloudfront.net/web-movement/static/pdfs/MovementTravelTimesMethodology-76002ded22.pdf

65. Na, Y., Guo, Y., Fu, Q., \& Yan, Y. (2015) An acoustic traffic monitoring system: Design and implementation. In: 2015 IEEE 12th Intl Conf on Ubiquitous Intelligence and Computing and 2015 IEEE 12th Intl Conf on Autonomic and Trusted Computing and 2015 IEEE 15th Intl Conf on Scalable Computing and Communications and Its Associated Workshops (UIC-ATC-ScalCom), 119-126. IEEE.

66. Oh, S., Byon, Y.J., Jang, K., \& Yeo, H. (2018) Short-term travel-time prediction on highway: A review on model-based approach. KSCE Journal of Civil Engineering, 22(1), 298-310.

67. Okutani, I., Stephanedes, Y.J. (1984) Dynamic prediction of traffic volume through Kalman filtering theory. Transportation Research Part B: Methodological, 18(1), 1-11.

68. Padiath, A., Vanajakshi, L., Subramanian, S.C., Manda, H. (2009) October. Prediction of traffic density for congestion analysis under Indian traffic conditions. In: 2009 12th International IEEE Conference on Intelligent Transportation Systems, 1-6). IEEE.

69. Pamuła, T. (2018) Impact of data loss for prediction of traffic flow on an urban road using neural networks. IEEE Transactions on Intelligent Transportation Systems, 20(3), 1000-1009.

70. Papageorgiou, M., Diakaki, C., Dinopoulou, V., Kotsialos, A., Wang, Y. (2003) Review of road traffic control strategies. In: Proceedings of the IEEE, 91(12), 2043-2067.

71. Perez-Murueta, P., Gómez-Espinosa, A., Cardenas, C., \& Gonzalez-Mendoza, M. (2019) Deep Learning System for Vehicular Re-Routing and Congestion Avoidance. Applied Sciences, 9(13), 2717.

72. Pfleiderer, R.H., \& Dieterich, M. (1995) New roads generate new traffic. World Transport Policy and Practice, 1(1), 29-31.

73. Philip, A. M., Ramadurai, G., \& Vanajakshi, L. (2018) Urban Arterial Travel Time Prediction Using Support Vector Regression. Transportation in Developing Economies, 4(1), 7. 
74. Polson, N. G., Sokolov, V. O. (2017) Deep learning for short-term traffic flow prediction. Transportation Research Part C: Emerging Technologies, 79, 1-17.

75. Raj, J., Bahuleyan, H., Vanajakshi, L. D. (2016) Application of data mining techniques for traffic density estimation and prediction. Transportation Research Procedia, 17, 321-330.

76. Rivas, J., Wunderlich, R., \& Heinen, S. J. (2016) Road vibrations as a source to detect the presence and speed of vehicles. IEEE Sensors Journal, 17(2), 377-385.

77. Saqib, M., Lee, C. (2010) Traffic control system using wireless sensor network. In: 2010 The 12th International Conference on Advanced Communication Technology (ICACT), 1, 352-357. IEEE.

78. Sen, R., Sevani, V., Sharma, P., Koradia, Z., \& Raman, B. (2009) Challenges in communication assisted road transportation systems for developing regions. NSDR'09.

79. Shao, H., Soong, B.H. (2016) Traffic flow prediction with long short-term memory networks (LSTMs). In: 2016 IEEE Region 10 Conference (TENCON), 2986-2989. IEEE.

80. Shen, W., Wynter, L. (2012) Real-time road traffic fusion and prediction with GPS and fixed-sensor data. In: 2012 15th International Conference on Information Fusion, 1468-1475. IEEE.

81. Shojafar, M., Cordeschi, N., Amendola, D., \& Baccarelli, E. (2015) Energy-saving adaptive computing and traffic engineering for real-time-service data centers. In: 2015 IEEE International Conference on Communication Workshop (ICCW), 1800-1806. IEEE.

82. Singh, G., Bansal, D., \& Sofat, S. (2014) Intelligent Transportation System for Developing Countries-A Survey. International Journal of Computer Applications, 85(3).

83. Sładkowski, A., \& Pamuła, W. eds. (2016) Intelligent transportation systems-problems and perspectives, Vol. 303. Springer International Publishing.

84. Smith, B .L., Demetsky, M. J. (1994) Short-term traffic flow prediction models-a comparison of neural network and nonparametric regression approaches. In: Proceedings of IEEE International Conference on Systems, Man and Cybernetics, 2, 1706-1709. IEEE.

85. Soua, R., Koesdwiady, A., Karray, F. (2016) Big-data-generated traffic flow prediction using deep learning and dempster-shafer theory. In: 2016 International joint conference on neural networks (IJCNN), 3195-3202. IEEE.

86. Teodorović, D., \& Dell'Orco, M. (2008) Mitigating traffic congestion: solving the ride-matching problem by bee colony optimization. Transportation Planning and Technology, 31(2), 135-152.

87. Tian, X. (2018) Research on Travel Time Prediction under Internet of Vehicles. In: 2018 International Conference on Intelligent Transportation, Big Data \& Smart City (ICITBS), 38-40. IEEE.

88. Underwood, R.T. (1990) Traffic management: an introduction.

89. Van Arem, B., Kirby, H.R., Van Der Vlist, M.J., Whittaker, J.C. (1997) Recent advances and applications in the field of short-term traffic forecasting. International journal of forecasting, 13(1), $1-12$.

90. Van Der Voort, M., Dougherty, M., Watson, S. (1996) Combining Kohonen maps with ARIMA time series models to forecast traffic flow. Transportation Research Part C: Emerging Technologies, 4(5), 307-318.

91. Wang Z., Li J., Fang M., \& Li, Y. (2015) A multimetric ant colony optimization algorithm for dynamic path planning in vehicular networks. Int J Distrib Sens Netw, 11(10).

92. Wang, Y., Papageorgiou, M., Messmer, A. (2008) Real-time freeway traffic state estimation based on extended Kalman filter: Adaptive capabilities and real data testing. Transportation Research Part A: Policy and Practice, 42(10), 1340-1358.

93. Wang, Z., Yu, Y., Ju, D. (2018) Analysis and Prediction of Urban Traffic Congestion Based on Big Data. International Journal on Data Science and Technology, 4(3), p.100.

94. Wedde, H.F., \& Senge, S. (2013) BeeJamA: A distributed, self-adaptive vehicle routing guidance approach. IEEE Transactions on Intelligent Transportation Systems, 14(4), 1882-1895.

95. Wen, F., Gen, M., \& Yu, X. (2011) A new multiobjective genetic algorithm for route selection. IEEJ Transactions on Electronics, Information and Systems, 131(3), 619-625.

96. Williams, B. M., Hoel, L. A. (2003) Modeling and forecasting vehicular traffic flow as a seasonal ARIMA process: Theoretical basis and empirical results. Journal of transportation engineering, 129(6), 664-672.

97. Williams, B.M. (2001) Multivariate vehicular traffic flow prediction: evaluation of ARIMAX modeling. Transportation Research Record, 1776(1), 194-200.

98. Won, M., Zhang, S., \& Son, S. H. (2017) WiTraffic: Low-cost and non-intrusive traffic monitoring system using WiFi. In: 2017 26th International Conference on Computer Communication and Networks (ICCCN), 1-9. IEEE. 
99. Wu, Y., Tan, H. (2016) Short-term traffic flow forecasting with spatial-temporal correlation in a hybrid deep learning framework. arXiv preprint arXiv:1612.01022.

100. Xie, Y., Zhang, Y., Ye, Z. (2007) Short-term traffic volume forecasting using Kalman filter with discrete wavelet decomposition. Computer-Aided Civil and Infrastructure Engineering, 22(5), 326-334.

101. Xu, D., Shi, Y. (2017) A combined model of random forest and multilayer perceptron to forecast expressway traffic flow. In: 2017 7th IEEE International Conference on Electronics Information and Emergency Communication (ICEIEC), 448-451. IEEE.

102. Xu, T., Li, X., \& Claramunt, C. (2018) Trip-oriented travel time prediction (TOTTP) with historical vehicle trajectories. Frontiers of earth science, 12(2), 253-263.

103. Yang, H.F., Dillon, T.S., Chen, Y.P.P. (2016) Optimized structure of the traffic flow forecasting model with a deep learning approach. IEEE transactions on neural networks and learning systems, 28(10), 2371-2381.

104. Yu, B., Wang, H., Shan, W., \& Yao, B. (2018) Prediction of bus travel time using random forests based on near neighbors. Computer Aided Civil and Infrastructure Engineering, 33(4), 333-350.

105. Yu, B., Yin, H., Zhu, Z. (2017) Spatio-temporal graph convolutional networks: A deep learning framework for traffic forecasting. arXiv preprint arXiv:1709.04875.

106. Yu, H., \& Lu, F. (2012) A multi-modal route planning approach with an improved genetic algorithm. Advances in Geo-Spatial Information Science, 193.

107. Zargari, S. A., Siabil, S. Z., Alavi, A. H., Gandomi, A. H. (2012) A computational intelligence-based approach for short-term traffic flow prediction. Expert Systems, 29(2), 124-142.

108. Zhang, D. and Kabuka, M.R., 2018. Combining weather condition data to predict traffic flow: a GRU-based deep learning approach. IET Intelligent Transport Systems, 12(7), pp.578-585.

109. Zhang, J., Zheng, Y., Sun, J., Qi, D. (2019) Flow prediction in spatio-temporal networks based on multitask deep learning. IEEE Transactions on Knowledge and Data Engineering, 32(3), 468-478.

110. Zhang, S., Wu, G., Costeira, J. P., \& Moura, J. M. (2017) Fcn-rlstm: Deep spatio-temporal neural networks for vehicle counting in city cameras. In: Proceedings of the IEEE international conference on computer vision, 3667-3676.

111. Zhang, Y., Huang, G. (2018) Traffic flow prediction model based on deep belief network and genetic algorithm. IET Intelligent Transport Systems, 12(6), 533-541.

112. Zhao, J., Gao, Y., Tang, J., Zhu, L., \& Ma, J. (2018) Highway Travel Time Prediction Using Sparse Tensor Completion Tactics and-Nearest Neighbor Pattern Matching Method. Journal of Advanced Transportation.

113. Zhao, Z., Chen, W., Wu, X., Chen, P.C., Liu, J. (2017) LSTM network: a deep learning approach for short-term traffic forecast. IET Intelligent Transport Systems, 11(2), 68-75.

114. Zhou, J., Chen, C.P., Chen, L., \& Zhao, W. (2013) A user-customizable urban traffic information collection method based on wireless sensor networks. IEEE Transactions on Intelligent Transportation Systems, 14(3), 1119-1128.

115. Zonoozi, A., Kim, J. J., Li, X. L., \& Cong, G. (2018) Periodic-CRN: A Convolutional Recurrent Model for Crowd Density Prediction with Recurring Periodic Patterns. In: IJCAI, 3732-3738.

116. Zou, Z., Gao, P., Yao, C. (2018) City-Level Traffic Flow Prediction via LSTM Networks. In: Proceedings of the 2nd International Conference on Advances in Image Processing, 149-153. 